\title{
Streptomyces Species Associated with Fissure Scab of Potato in South Africa Including Description of $S$. Resiliuntiscabiei Sp. Nov.
}

\author{
Elsie Margaretha Cruywagen \\ Agricultural Research Council-Vegetables, Industrial and Medicinal Plants (ARC-VIMP), Crop Protection Division \\ Rian Pierneef \\ Agricultural Research Council, Biotechnology Platform, Onderstepoort \\ Kgothatso Andronicah Chauke \\ Agricultural Research Council-Vegetables, Industrial and Medicinal Plants (ARC-VIMP), Crop Protection Division \\ Brightness Zama Nkosi \\ Agricultural Research Council-Vegetables, Industrial and Medicinal Plants (ARC-VIMP), Crop Protection Division \\ David Labeda \\ Dr. David P. Labeda Consulting, 137 South Duke Street, Lancaster \\ Michele Cloete ( $\nabla$ cloetemi@arc.agric.za) \\ Agricultural Research Council Vegetable and Ornamental Plants https://orcid.org/0000-0002-9558-4891
}

\section{Research Article}

Keywords: Fissure scab, Streptomyces, pathogenicity island, potato disease

Posted Date: May 24th, 2021

DOl: https://doi.org/10.21203/rs.3.rs-326303/v1

License: @ (1) This work is licensed under a Creative Commons Attribution 4.0 International License. Read Full License 


\section{Abstract}

Streptomyces species are the causal agents of several scab diseases on potato tubers. A new type of scab symptom, caused by Streptomyces species, was observed in South Africa from 2010 onwards. The disease was initially thought to be caused by a single Streptomyces species, however, subsequent isolations from similar symptoms on other potato tubers revealed diversity of the Streptomyces isolates. The objective of this study was to characterise these isolates in order to determine which species are involved in the disease. This was done by sequencing and phylogenetic analyses of the 16S rDNA as well as five housekeeping genes, investigation of growth on different culture media, standard phenotypic tests and scanning electron microscopy of culture morphology. The presence of the pathogenicity island (PAI) present in plant pathogenic Streptomyces species was also investigated. The genomes of eight isolates selected from the three main clades identified, were sequenced and annotated to further clarify species boundaries. Two isolates of each of the three main clades were also inoculated onto susceptible potato cultivars in order to establish the pathogenicity of the species. The results of the phylogenetic and genome analyses revealed that there are three main species involved, namely, S. werraensis, $S$. pseudogriseolus and a novel Streptomyces species that is described here as Streptomyces resiliuntiscabiei sp. nov. The glasshouse trial results showed that all three of the Streptomyces species are capable of producing fissure scab symptoms. None of the Streptomyces isolates from fissure scab contained the full PAl and the mechanism of disease initiation still needs to be determined.

\section{Introduction}

Streptomyces species are causal agents of some of the most wide-spread and economically important diseases in potato production worldwide (Braun et al. 2017; Wanner 2006, 2009). Common scab is caused by species in the Streptomyces scabiei complex. Other related Streptomyces species are the causal agents of netted scab in Europe (Scholte and Labruyére 1985) and russet scab in North America and Japan (Faucher et al. 1993; Oniki et al. 1986). All of these diseases are caused by complexes of Streptomyces species and have large variations in symptom expression (Bouchek-Mechiche et al. 2000; Wanner 2006, 2009).

Plant pathogenicity in the Streptomyces genus has been proven to be based on a specific toxin, thaxtomin, which is produced by pathogenic strains causing common scab. Genes encoding enzymes for the synthesis of thaxtomin ( $t x t A$, $t x t B$, $t x t C$, and nos) are located in a pathogenicity island (PAI) (Loria et al. 2006). Other genes encoding virulence factors also found on the PAl in pathogenic Streptomyces species include tomatinase (tomA) and the necrosis-inducing protein (nec1) (Wanner 2006). Thaxtomin inhibits cellulose biosynthesis and is able to induce plant cell hypertrophy in growing plant tissues (Fry and Loria 2002; Scheible et al. 2003), thereby causing the scabs on potato tubers (Fiers et al. 2012). Tomatinase is responsible for plant defence suppression (Kers et al. 2005) by detoxification of tomatin, an anti-microbial saponin (Roldán-Arjona et al. 1999). The nec1 gene encodes a small necrogenic protein with an unknown plant cell target (Bukhalid et al. 1998) that may be involved in plant defence suppression (Joshi et al. 2007).

The availability of whole genome sequences for thousands of organisms have enabled researchers to study fields like the evolution of organisms (Chandra and Chater 2014 ) and the occurrence of horizontal gene transfer (HGT) more effectively (Armijos-Jaramillo et al. 2017). HGT has been shown to be responsible for the emergence of several new plant and human pathogens (De la Cruz and Davies. 2000; Friesen et al. 2006; Garcia-Vallvé et al. 2000). In Streptomyces, it has been demonstrated that PAl present in pathogenic Streptomyces species could confer pathogenicity to non-pathogenic organisms during mating experiments in the laboratory (Kers et al. 2005; Zhang et al. 2016; Zhang and Loria 2017). Bukhalid et al. (2002) also presented evidence of HGT between Streptomyces species causing the emergence of multiple plant-pathogenic species. This mechanism can therefore lead to non-pathogens acquiring pathogenicity genes and causing diseases that previously did not exist.

The genus Streptomyces has undergone extensive revisions and currently contains around 800 species (http://www.bacterio.net/streptomyces.html), of which most are saprophytic and present in large numbers in the soil (Janssen 2006). There have been numerous name changes and taxonomic revisions of the species in this genus since the first description of the common scab pathogen as Oöspora scabies by Thaxter in 1892 (Güssow 1914). One of the most comprehensive reviews was initiated by the International Streptomyces Project (ISP) committee, which was established in 1963. This provided a standard set of tests to use in describing Streptomyces species (Shirling and Gottlieb 1966). However, since the advent of DNA sequencing (reviews of Streptomyces based on DNA sequencing: Labeda et al. 2012; Labeda et al. 2017) and more recently whole genome sequencing (Sutcliffe et al. 2012; Jain et al. 2018; Parks et al. 2018), these methods have been superseded in the description of bacterial species. However, many Streptomyces descriptions still include results of biochemical tests, as these may be an indication of useful secondary metabolites produced by the Streptomyces species. 
In South Africa, Gouws and McLeod (2012) described a new disease of potatoes, associated with Streptomyces species. The symptoms on potato tubers consisted of deep longitudinal cracks with scab-like lesions (Fig. 1a), and was termed "fissure scab". These blemishes differ from common scab (Fig. 1b) and growth cracks (Fig. 1c) in the star shaped fissures that is commonly associated with fissure scab. The causal agent was identified as a Streptomyces species related to $S$. vinaceus, $S$. malachiticus, S. werraensis, S. cyaneus and $S$. pseudogriseolus. The four isolates that were sequenced during the initial description of the disease were identical (Gouws and McLeod 2012), leading researchers to believe that a single Streptomyces species was responsible for the disease. However, subsequent isolations from fissure scab symptoms over the last eight years have revealed considerable morphological variation in the Streptomyces isolates obtained from these symptoms. Further investigations into the causal agents of fissure scab was therefore initiated and the results of these studies are presented here.

\section{Materials And Methods}

\section{Sample collection and isolation}

Potato tuber samples, displaying scab symptoms (as described by Gouws and McLeod (2012)), were collected from various potato production regions in South Africa. Isolation for Streptomyces from potatoes was done according to Loria and Davis (1989). The potatoes were washed and surface disinfested with $70 \%$ ethanol for $1 \mathrm{~min}$. The potatoes were then rinsed thoroughly with sterile distilled water. The surface of the lesions was removed and discarded. The tissue under the scab lesion was cut into smaller pieces and crushed in $1 \mathrm{~mL}$ of sterile distilled water. Approximately $0.1 \mathrm{~mL}$ of the crushed tissue suspension was streaked onto Inorganic Salt Starch agar (ISSA - ISP medium 4 according to Shirling and Gottlieb (1966)). Plates were incubated at $28^{\circ} \mathrm{C}$ for 5 days. Colonies resembling Streptomyces species were selected and purified by streaking on ISSA plates. Isolates were preserved as spore suspensions in $20 \% \mathrm{glycerol}$ at $-80{ }^{\circ} \mathrm{C}$ in the Streptomyces bacterial collection at the ARC-VIMP.

\section{DNA extraction, PCR amplification and sequencing}

Streptomyces isolates were grown on ISSA for 5 days at $30^{\circ} \mathrm{C}$, where after DNA was extracted for PCR and sequencing using the Zymo Research fungal/bacterial DNA isolation kit (Zymo Research Corporation, Irvine CA, USA). DNA was amplified by PCR using commonly used primers for bacterial characterisation (Bukhalid et al. 2002; Guo et al. 2008).

The PCR reactions consisted of $1 \mu \mathrm{L}$ of template DNA, $1 \mu \mathrm{L}$ of each primer, $12.5 \mu \mathrm{L}$ of GC Tempase Mastermix II (Ampliqon A/S, Denmark) made up to $25 \mu \mathrm{L}$ with PCR grade water. Conditions for the PCR included an initial denaturing at $95^{\circ} \mathrm{C}$ for 15 min, followed by 35 cycles of denaturation at $95^{\circ} \mathrm{C}$ for $30 \mathrm{~s}$, annealing of primers at $55^{\circ} \mathrm{C}$ (for $16 \mathrm{~s}$ rRNA), $63^{\circ} \mathrm{C}$ (for rpoB and recA), $65^{\circ} \mathrm{C}$ (for trpB), $60{ }^{\circ} \mathrm{C}$ (for atpD), and $58{ }^{\circ} \mathrm{C}$ (for gyrB) for $20 \mathrm{~s}$, elongation at $72{ }^{\circ} \mathrm{C}$ for $30 \mathrm{~s}$ and a final extension step at $72{ }^{\circ} \mathrm{C}$ for 10 min. PCR products were visualized on $1 \%$ agarose gels, stained with ethidium bromide.

Forward and reverse strands of PCR products were sequenced by Inqaba Biotec (Pretoria, South Africa). The forward and reverse sequences were assembled and consensus sequences generated using CLC Genomics Workbench 10.0 (https://www.qiagenbioinformatics.com/). Sequences of type strains of Streptomyces species were downloaded from GenBank (https://blast.ncbi.nlm.nih.gov/) and aligned with newly generated sequences with the online version of MAFFTv.7

(http://mafft.cbrc.jp/alignment/server/index.html).

\section{Phylogenetic analyses}

Phylogenetic analyses were conducted using PhyML 3.0 (Guindon and Gascuel 2003). Initial Maximum Likelihood trees of individual genes were constructed to check whether the different gene regions resulted in congruent tree topologies. After checking for congruence, the protein coding genes were combined into a single dataset. Selection of models of nucleotide substitution for the PhyML analyses, implementing the Akaike information criterion (AIC), was determined with jModeltest 2.1.7 (Guindon and Gascuel 2003; Darriba et al. 2012). Phylogenetic trees were mid-point rooted and bootstrap analysis was performed to determine branching point confidence intervals (1000 replicates). An initial analysis of 16S rDNA with all described Streptomyces species and all isolates obtained from fissure scab was conducted in order to determine which species are closely related to the fissure scab isolates. All subsequent analyses only included the selected subset of isolates.

\section{Genome sequencing and annotation}

Eight Streptomyces isolates were sequenced on Illumina HiSeq 2500 producing 2*125 bp paired-end reads. Quality control was done using FastQC v0.11.5 (Andrews 2010) and Trimmomatic v0.36 (Bolger et al. 2014). Genome assemblies were generated using SPAdes 
v3.12.0 (Bankevich et al. 2012) and the quality of the resulting assemblies evaluated by QUAST v4.6.3 (Gurevich et al. 2013). The assemblies were annotated with RAST (Overbeek et al. 2013). Average nucleotide identity (ANI) and average amino acid identity (AAI) matrices were calculated using the enveomics toolbox (Rodriguez-R and Konstantinidis 2016).

To elucidate possible mechanisms of pathogenicity, local BLAST searches for commonly found pathogenicity associated genes in Streptomyces were conducted on CLC Genomics Workbench. Annotated genomes were searched for virulence and pathogenicity associated genes.

\section{Morphology and phenotypic analysis}

Isolates from the three main clades identified by sequencing were selected for morphological investigation. Colony morphology was investigated on Yeast extract-Malt extract agar (YMA, ISP medium 2), Oatmeal agar (OA, ISP medium 3), ISSA, Gycerol-Asparagine agar (GA, ISP medium 5) and Tyrosine agar (TA, ISP medium 7). Isolates were streaked onto the different culture media, incubated at $30{ }^{\circ} \mathrm{C}$ in the dark and investigated for colony colour and pigment production after 7 and 14 days.

Spore chain morphology of isolates grown on OA for 7 days at $30^{\circ} \mathrm{C}$ was investigated by scanning electron microscopy (SEM). Material was prepared by immersion in $2.5 \%$ glutaraldehyde in $0.075 \mathrm{M}$ phosphate buffer $(\mathrm{pH} 7)$ for $1 \mathrm{~h}$. The specimens were washed three times (10 min each) in $0.075 \mathrm{M}$ phosphate buffer and fixed in $0.5 \%$ aqueous osmium tetroxide for $1-2 \mathrm{~h}$. The material was washed three times in distilled water and dehydrated (10 min each) in 30\%, 50\%, 70\%, 90\%, and three times in 100\%, ethanol. Hexamethyldisilizane (HMDS) was used to dry the material, where after it was mounted on aluminium stubs and coated with carbon. A Zeiss Crossbeam 540 FEG SEM was used to visualize the material.

Carbohydrate utilisation was determined using a 1\% concentration of each carbon source (L-arabinose, D-fructose, D-glucose, l-inositol, Dmannitol, raffinose, rhamnose, sucrose and D-xylose) added to the carbon utilization medium (ISP medium 9 - Shirling and Gottlieb 1966) and rated for growth 14 days after incubation at $25^{\circ} \mathrm{C}$. The optimum temperatures for growth were assessed using ISP medium 1 at a range of $5-45^{\circ} \mathrm{C}$, with $5^{\circ} \mathrm{C}$ intervals. Tolerance to sodium chloride was established using basal medium 5339 (10 g casein peptone $\mathrm{L}^{-1}, 5$ g yeast extract $\left.\mathrm{L}^{-1}, 15 \mathrm{~g}_{\text {agar }} \mathrm{L}^{-1}\right)$ supplemented with $0-15 \%(\mathrm{w} / \mathrm{v})$ sodium chloride with $2.5 \%$ intervals. The $\mathrm{pH}$ tolerance of isolates was tested on YMA plates at pH levels from 4 to 12. The $\mathrm{pH}$ levels of 4, 5.5, 7, 8.5 and 10.0 were adjusted with $\mathrm{NaOH}$ or $\mathrm{HCl}$ before autoclaving, and $\mathrm{pH} 11.5$ was adjusted from $\mathrm{pH} 10$ after autoclaving.

\section{Screening of isolates by tuber slice assay}

Initial screening of all Streptomyces isolates obtained from fissure scab symptoms were conducted to select virulent isolates for use in a greenhouse trial. Potato tubers cv. Mondial, were purchased from a supermarket in Pretoria. The tubers were washed thoroughly with water, disinfected in $1 \%$ sodium hypochlorite $(\mathrm{NaClO})$ for $5 \mathrm{~min}$, rinsed with sterile distilled water and air dried under a laminar flow hood. Inoculum was prepared for each isolate by making spore suspensions in sterile water in 20 mL McCartney bottles from mycelia and spores grown on ISSA plates for 5 days. Disinfected tubers were sliced into $7 \mathrm{~mm}$ thick slices with a sterilized knife and placed on top of moistened sterile filter paper in $90 \mathrm{~mm}$ plastic Petri dishes. A $10 \mu \mathrm{L}$ aliquot of inoculum was pipetted in the centre of each tuber slice. Sterile water was included as a negative control. Petri dishes were placed in boxes lined with moist paper towels and incubated at $25{ }^{\circ} \mathrm{C}$ in the dark for 5 days. Treatments were replicated three times and arranged in a completely randomized design. The tubers were evaluated visually for the presence and size of the necrotic area on the tuber slice.

\section{Pathogenicity trial}

The pathogenicity of Streptomyces strains was investigated using two cultivars known to be susceptible to fissure scab, namely, Mondial and Innovator. Pots (25 cm diameter) were sterilized with 1\% sodium hypochlorite and rinsed with sterile water. Compost was sterilized using a soil pasteurizer at $300{ }^{\circ} \mathrm{C}$ for $30 \mathrm{~min}$ and sterilized pots were filled halfway with the compost. One potato tuber was placed on top of the compost in each pot, after which the pots were filled with silica sand. The pots were maintained in a greenhouse at $25-28{ }^{\circ} \mathrm{C}$ and irrigated three times a week. Three isolates from each of the three main Streptomyces clades identified in the phylogenetic analysis were selected based on results from the tuber slice assay. The isolates were grown on ISSA for 7 days and scraped off to make a spore suspension to be used as inoculum.

At the tuber initiation stage, the pots were inoculated with the spore suspensions and placed in a randomized complete block design with 10 replicates. The control pots were inoculated with sterile distilled water. Potatoes were harvested three months after planting and evaluated for fissure scab symptoms using a custom rating scale: 
Lesion length (LT):

$1=1-25 \%$ of tuber length

$2=25-50 \%$ of tuber length

$3=50-75 \%$ of tuber length

$4=75-100 \%$ of tuber length

Lesion depth (LD):

$1=$ lesion depth is superficial

2 = lesion depth is medium deep

$3=$ lesion depth is very deep

Scab Index $=($ LTxLD $) / 100$

Streptomyces species were re-isolated from potatoes with fissure scab symptoms. The isolates were purified and identified in order to fulfil Koch's postulates. Data were analysed with SAS software (SAS Institute, Inc., 1999) to determine significant differences between treatments.

\section{Results}

Sample collection and isolation

A total of 142 Streptomyces isolates were obtained from tubers with symptoms that resemble fissure scab. The symptomatic tubers were collected from all of the major potato production regions in South Africa.

Phylogenetic analyses

Newly generated DNA sequences from this study are available from GenBank with accession numbers MK934844-MK934992 and MK956209- MK956788. Isolates included in the phylogenetic analyses are listed in Table 1. Alignment of sequences for individual datasets yielded 1,367 bp (16S), 496 bp (atpD), 428 bp (gyrB), 504 bp (recA), 540 bp (rpoB) and 571 bp (trpB). The combined dataset of the 5 housekeeping genes yielded a dataset of 2,539 bp. The best substitution model for both $16 \mathrm{~S}$ and combined datasets was GTR+I+G.

An initial ML tree consisting of all Streptomyces species and all fissure scab isolates were constructed (Fig. S1 supplementary material). The majority of the isolates (60\%) obtained from fissure scab symptoms grouped into three clades. Clade 1 (17.6\%) grouped with $S$. werraensis, clade 2 (17.6\%) grouped close to S. pseudogriseolus and S. gancidicus, while clade 3 (24.6\%) grouped close to S. flaveolus. The other 49 isolates grouped into 37 different clades and these smaller groupings were not investigated further in the current study.

The tree topologies for the individual housekeeping genes were all congruent (data not presented) and showed concordance with the 16S rDNA tree topology (Fig. 2). The combined tree (Fig. 3) confirmed that the clade 1 isolates belong to species $S$. werraensis with a bootstrap support of $99 \%$. Clade 2 isolates grouped close to S. pseudogriseolus, S. rubiginosus and S. gancidicus, and clade 3 isolates grouped close, but clearly distinct from $S$. flaveolus with a bootstrap support of $99 \%$.

Genome sequencing and annotation

Genomes were sequenced at 100 x coverage and assembled into 82, 121, 174, 118, 99, 85, 130, 113 contigs for isolates 057 , N92, N26, FS66, FS75, FS97, FS94 and FS70, respectively. This Whole Genome Shotgun project has been deposited at DDBJ/ENA/GenBank under the accession numbers SAMN16577101, SAMN16577100 and SAMN13430412-SAMN13430417.

The ANI and AAI with closely related Streptomyces are shown in Fig. 4; however, no genome sequence for $S$. werraensis was available. The values confirmed that clade 3 (isolates N26, FS66, FS70 and FS75) is a distinct species from S. flaveolus with 84\% ANI and 78\% AAI. Clade 2 isolates (isolates N92 and FS94) are similar to S. pseudogriseolus and S. gancidicus which belong to one species as these isolates share $99 \% \mathrm{AAl}$ and $\mathrm{ANI}$. 
The PAI commonly found in plant pathogenic Streptomyces species were not present in any of the six genomes. However, all six of the isolates contained analogues to the Staphylococcal pathogenicity islands (SaPI), while the clade 3 isolates also contained the Golgiassociated plant pathogenesis-related protein 1 gene.

\section{Morphology and phenotypic analysis}

Culture morphology on OA is shown in Fig. 5 a-c. Isolates belonging to clade 3 produced yellow diffusible pigments on all culture media (Fig. 5c), which made it possible to distinguish these cultures from clades 1 (Fig. 5a) and 2 (Fig. 5b). Some cultures in clade 2 produced a reddish-brown pigment on OMA. SEM revealed that clades 1 (Fig. 6a) and 3 (Fig. 6e) had mycelia in open loops (Retinaculiaperti), while clade 2 (Fig. 6c) formed simple spirals (Spirales). The spores surfaces of all three clades were spiny (Fig. 6b, d, f), with some spores in clade 1 exhibiting a warty surface (Fig. 6b). Although the culture morphology of clades 1 and 2 were similar, the distinct spirals of clade 2 and the profusion of single spores from clade 1 made it possible to distinguish between these clades.

Isolates from clades 1 and 3 were able to utilize L-arabinose, D-fructose, D-glucose, l-inositol, D-mannitol, raffinose, rhamnose, sucrose and D-xylose as sole carbon sources, however, utilization of sucrose, fructose and raffinose by isolates from clade 2 were doubtful ( \pm ). Isolates from all three clades were able to grow between $\mathrm{pH} 5.0-\mathrm{pH} 11$ and were tolerant to $\mathrm{NaCl}$ of up to $7.5 \%$, but were inhibited by $10 \% \mathrm{NaCl}$. Growth studies were carried out on Streptomyces resiliuntiscabiei, sp. nov. and it was able to grow between 10 and $45^{\circ} \mathrm{C}$, with optimal growth between 30 and $35^{\circ} \mathrm{C}$. Streptomyces flaveolus cannot utilize raffinose (Shirling and Gottlieb 1968), confirming that $S$. resiliuntiscabiei sp. nov. represents a distinct novel species.

\section{Tuber slice assay}

The three isolates causing the largest lesions from each of the three main phylogenetic clades were selected to use to test for pathogenicity in the glasshouse trial. These were isolates 057, FS29, FS97 (clade 1), FS33, FS94, N92 (clade 2), N26, FS70 and FS75 (clade 3).

\section{Pathogenicity trial}

Isolates from all three clades were able to cause symptoms similar to those seen in fissure scab (Fig. 7). The results from the glasshouse trial disease ratings are given in Fig. 8. In general, Innovator showed a higher scab index than Mondial, however it is not a statistically significant difference. Isolates FS97 (clade 1) and N26 (clade 3) resulted in a significant higher scab index on Innovator than on Mondial $(p<0.05)$. However, there is large variation in the scab index within the same treatments.

Re-isolation and identification of pathogens from diseased tubers confirmed that the inoculated organisms were responsible for the disease symptoms observed.

\section{Discussion}

This is the first comprehensive survey to identify the Streptomyces isolates associated with fissure scab in South Africa. The three main clades, comprising $60 \%$ of the isolates obtained from fissure scab symptoms from $2010-2018$, were identified as $S$. werraensis, $S$. pseudogriseolus and $S$. resiliuntiscabiei sp. nov. Full genome sequences were generated for eight isolates selected from the three species. Glasshouse trials with the three species revealed that all three species are capable of causing fissure scab symptoms on potato cvs. Mondial and Innovator. The PAl genes present in the common scab pathogens, comprised of thaxtomin, tomatinase and nec1, are absent in most of the isolates, with only the nec 1 gene being present in some isolates of $S$. resiliuntiscabiei (data not shown).

Horizontal gene transfer of the PAl has been proven to occur in Streptomyces species and to lead to the emergence of new pathogenic species (Bukhalid et al. 1998, 2002; Kers et al. 2005; Zhang et al. 2016; Zhang et al. 2017). However, this PAl is absent in the fissure scab isolates, and this leads to the question of the mechanism of disease development. The genomes that were generated will be investigated further for indications on which genes may be responsible for initiating the cracks that are the main characteristic of the fissure scab symptoms.

The advent of DNA sequencing and more recently genome sequencing has removed the necessity of doing scores of phenotypic tests in the hope of finding morphological and phenotypic differences in order to describe a novel bacterial species. These tests are still useful in finding novel biochemical products produced by the ubiquitous Streptomyces genus, however, time and money spent by taxonomists will be greatly reduced without having to do these tests (Sutcliffe et al. 2012), while increasing the rate at which species can be described. As more full genomes become available, the use of the ANI and AAl statistics of these genomes will aid in making decisions on where to 
delimit species. The 16S rDNA as well as the combined phylogenetic trees in this study were inconclusive on the identities of clades 2 and 3. However, the ANI and AAI matrixes conclusively showed that clade 2 strains are members of $S$. pseudogriseolus, while clade 3 strains are not members of $S$. flaveolus, but represent a novel species for which the name $S$. resiliuntiscabiei sp. nov. is proposed. The phenotypic, phylogenetic and genomic data support this proposal and the formal description of this new species follows below.

\section{Description of Streptomyces resiliuntiscabiei sp. nov.}

Streptomyces resiliuntiscabiei (resiliunt for the Latin word meaning "crack", describing the symptoms on the potato tubers).

Gram-stain positive, aerobic, non-motile, alkali tolerant and thermotolerant, with good growth of hyphae that are extensively branched with aerial hyphae that differentiate into open loops of spores (Retinaculiaperti). Good growth on ISP 3 and ISP 4, poor growth on ISP 2 and 5 , and moderate growth on ISP 7. Colonies on ISP 3 are white initially, turning light grey after sporulation, surrounded with white margins. Diffusible yellow pigment discolours media. Isolates able to utilize L-arabinose, D-fructose, D-glucose, l-inositol, D-mannitol, raffinose, rhamnose, sucrose and D-xylose as sole carbon sources. Grow from pH 5.0-pH11. Grow well in the presence of 0-5\% $\mathrm{NaCl}$ and can tolerate up to $7.5 \% \mathrm{NaCl}$, but were inhibited at concentrations of $10 \%$ and higher. Growth between $10{ }^{\circ} \mathrm{C}$ and $45^{\circ} \mathrm{C}$, with optimal growth between $30{ }^{\circ} \mathrm{C}$ and $35^{\circ} \mathrm{C}$.

The strains FS70, N26, FS75 and FS80 were isolated from potato tubers with fissure scab symptoms in the Limpopo Province of South

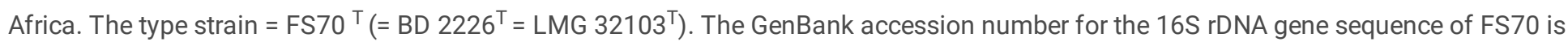
MK934943 and the genome accession number is SAMN13430412.

\section{Declarations}

Funding - Funding was provided by Potatoes South Africa (PSA) the National Research Foundation Research and Technology Fund (NRFRTF) [UID98601] and the NRF-Technology and Human Resources in Industry Partnership (NRF-THRIP) [UID 96369]

Conflicts of interest/Competing interests - No conflict of interest

Availability of data and material - all sequence data have been deposited on GenBank and the type culture of the novel species was deposited into 2 international culture collections.

Code availability - Not applicable

Authors' contributions Conceptualization: M. Cloete, Methodology: M. Cloete, E. Cruywagen, R. Pierneef, D. Labeda; Formal analysis and investigation: K. Chauke, Z. Nkosi, E. Cruywagen, R. Pierneef; Writing - original draft preparation: E. Cruywagen, K. Chauke; Writing - review and editing: M. Cloete, D. Labeda, R. Pierneef, Z. Nkosi; Funding acquisition: M. Cloete; Supervision: M. Cloete, E. Cruywagen.

Ethics: No ethical issues to declare

\section{Acknowledgments}

Mr. Allan Hall of the laboratory for microscopy and microanalysis at the University of Pretoria is thanked for assistance with electron microscopy. Ms Kate Phetla and Mr Nthako Supu is thanked for assistance in collection of samples as well as assistance in the laboratory and glasshouse trials. We further acknowledge Agricultural Research Council - Vegetable, Industrial and Medicinal Plants (ARC-VIMP) for providing laboratory and glasshouse facilities for conducting the study.

\section{References}

1. Andrews S (2010) Babraham bioinformatics-FastQC a quality control tool for high throughput sequence data. URL: https://www. bioinformatics. babraham. ac. uk/projects/fastqc/

2. Armijos-Jaramillo V, Santander-Gordón D, Soria R, Pazmiño-Betancourth M, Echeverría MC (2017) A whole genome analysis reveals the presence of a plant PR1 sequence in the potato pathogen Streptomyces scabies and other Streptomyces species. Mol Phylogenet Evol 114:346-352

3. Bankevich A, Nurk S, Antipov D, Gurevich AA, Dvorkin M, Kulikov AS, Lesin VM, Nikolenko SI, Pham S, Prjibelski AD, Pyshkin AV (2012) SPAdes: a new genome assembly algorithm and its applications to single-cell sequencing. J Comput Biol 19(5):455-477

4. Bolger AM, Lohse M, Usadel B (2014) Trimmomatic: a flexible trimmer for Illumina sequence data. Bioinform 30(15):2114-2120 
5. Bouchek-Mechiche K, Gardan L, Normand P, Jouan B (2000) DNA relatedness among strains of Streptomyces pathogenic to potato in France: description of three new species, $S$. europaeiscabiei sp. nov. and $S$. stelliscabiei sp. nov. associated with common scab, and $S$. reticuliscabiei sp. nov. associated with netted scab. Int J Syst Evol Microbiol 50(1):91-99

6. Braun S, Gevens A, Charkowski A, Allen C, Jansky S (2017) Potato common scab: A review of the causal pathogens, management practices, varietal resistance screening methods, and host resistance. American J Potato Res 94(4):283-296

7. Bukhalid RA, Chung SY, Loria R (1998) nec1, a gene conferring a necrogenic phenotype, is conserved in plant-pathogenic Streptomyces spp. and linked to a transposase pseudogene. Mol Plant Microbe In 11(10):960-967

8. Bukhalid RA, Takeuchi T, Labeda D, Loria R (2002) Horizontal transfer of the plant virulence gene, nec1, and flanking sequences among genetically distinct Streptomyces strains in the Diastatochromogenes cluster. Appl Environ Microbiol 68(2):738-744

9. Chandra G, Chater KF (2014) Developmental biology of Streptomyces from the perspective of 100 actinobacterial genome sequences. FEMS Microbiol Rev 38(3):345-379

10. Darriba D, Taboada GL, Doallo R, Posada D (2012) jModelTest 2: more models, new heuristics and parallel computing. Nat Methods 9(8):772

11. De la Cruz F, Davies J (2000) Horizontal gene transfer and the origin of species: lessons from bacteria. Trends Microbiol 8(3):128133

12. Faucher $E$ (1993) Characterization of Streptomycetes causing russet scab in Québec. Plant Dis 77(12):1217-1220

13. Fiers M, Edel-Hermann V, Chatot C, Le Hingrat Y, Alabouvette C, Steinberg C (2012) Potato soil-borne diseases. A review. Agron Sustain Dev 32(1):93-132

14. Friesen TL, Stukenbrock EH, Liu Z, Meinhardt S, Ling H, Faris JD, Rasmussen JB, Solomon PS, McDonald BA, Oliver RP (2006) Emergence of a new disease as a result of interspecific virulence gene transfer. Nat Genet 38(8):953-956

15. Fry BA, Loria R (2002) Thaxtomin A: evidence for a plant cell wall target. Phys Mol Plant Path 60(1):1-8

16. Garcia-Vallvé S, Romeu A, Palau J (2000) Horizontal gene transfer in bacterial and archaeal complete genomes. Genome Res 10(11):1719-1725

17. Gouws R, McLeod A (2012) Fissure scab, a new symptom associated with potato common scab caused by a Streptomyces $\mathrm{sp}$. in South Africa. Plant Dis 96(8):1223

18. Guindon S, Gascuel O (2003) A simple, fast, and accurate algorithm to estimate large phylogenies by maximum likelihood. Syst Biol 52(5):696-704

19. Guo Y, Zheng W, Rong X, Huang Y (2008) A multi-locus phylogeny of the Streptomyces griseus 16S rRNA gene clade: use of multilocus sequence analysis for streptomycete systematics. Int J Syst Evol Microbiol 58:149-159

20. Gurevich A, Saveliev V, Vyahhi N, Tesler G (2013) QUAST: quality assessment tool for genome assemblies. Bioinformatics 29(8):1072-1075

21. Güssow HT (1914) The systematic position of the organism of the common potato scab. Science 39:431-433

22. Jain C, Rodriguez-R LM, Phillippy AM, Konstantinidis KT, Aluru S (2018) High throughput ANI analysis of 90K prokaryotic genomes reveals clear species boundaries. Nat Commun 9(1):5114

23. Janssen PH (2006) Identifying the dominant soil bacterial taxa in libraries of $16 \mathrm{~S}$ rRNA and $16 \mathrm{~S}$ rRNA genes. Appl Environ Microbiol 72(3):1719-1728

24. Joshi M, Rong X, Moll S, Kers J, Franco C, Loria R (2007) Streptomyces turgidiscabies secretes a novel virulence protein, Nec1, which facilitates infection. Mol Plant Microbe In 20(6):599-608

25. Kers JA, Cameron KD, Joshi MV, Bukhalid RA, Morello JE, Wach MJ, Gibson DM, Loria R (2005) A large, mobile pathogenicity island confers plant pathogenicity on Streptomyces species. Mol Microbiol 55(4):1025-1033

26. Labeda DP, Goodfellow M, Brown R, Ward AC, Lanoot B, Vanncanneyt M, Swings J, Kim SB, Liu Z, Chun J, Tamura T (2012) Phylogenetic study of the species within the family Streptomycetaceae. Antonie Van Leeuwenhoek 101(1):73-104

27. Labeda DP, Dunlap CA, Rong X, Huang Y, Doroghazi JR, Ju KS, Metcalf WW (2017) Phylogenetic relationships in the family Streptomycetaceae using multi-locus sequence analysis. Antonie Van Leeuwenhoek 110(4):563-583

28. Loria R, Davis R (1988) III. Gram-positive bacteria, B. Streptomyces scabies.. In: Schaad NW (ed) Laboratory guide for identification of plant pathogenic bacteria. American Phytopathological Society, St Paul, pp 114-119

29. Loria R, Kers J, Joshi M (2006) Evolution of plant pathogenicity in Streptomyces. Ann Rev Phytopath 44:469-487 
30. Oniki M, Suzui T, Araki T, Sonoda R, Chiba T, Takeda T (1986) Causal agent of russet scab of potato. Bull Natl Inst Agro-Environ Sci 2:56-59

31. Overbeek R, Olson R, Pusch GD, Olsen GJ, Davis JJ, Disz T, Edwards RA, Gerdes S, Parrello B, Shukla M, Vonstein V (2013) The SEED and the rapid annotation of microbial genomes using Subsystems Technology (RAST). Nucleic Acids Res 42(D1):D206-D214

32. Parks DH, Chuvochina M, Waite DW, Rinke C, Skarshewski A, Chaumeil PA, Hugenholtz P (2018) A proposal for a standardized bacterial taxonomy based on genome phylogeny. BioRxiv, p.256800

33. Rodriguez -RLM, Konstantinidis KT (2016) The enveomics collection: a toolbox for specialized analyses of microbial genomes and metagenomes. PeerJ Preprints 4:e1900v1 https://doi.org/10.7287/peerj.preprints.1900v1

34. Roldán-Arjona T, Pérez-Espinosa A, Ruiz-Rubio M (1999) Tomatinase from Fusarium oxysporum f. sp. lycopersici defines a new class of saponinases. Mol Plant Microbe In 12(10):852-861

35. SAS Institute, Inc (1999), SAS/STAT User's Guide, Version 9.4, 1st printing, Volume 2. SAS Institute Inc, SAS Campus Drive, Cary, North Carolina 27513

36. Scheible WR, Fry B, Kochevenko A, Schindelasch D, Zimmerli L, Somerville S, Loria R, Somerville CR (2003) An Arabidopsis mutant resistant to thaxtomin A, a cellulose synthesis inhibitor from Streptomyces species. Plant Cell 15(8):1781-1794

37. Scholte K, Labruyere RE (1985) Netted scab: a new name for an old disease in Europe. Potato Res 28(4):443-448

38. Shirling ET, Gottlieb D (1966) Methods for characterization of Streptomyces species. Int J Syst Evol Microbiol 16(3):313-340

39. Shirling ET, Gottlieb D (1968) Cooperative description of type cultures of Streptomyces. II. Species descriptions from first study. Int J Syst Bacteriol 18(2):69-189

40. Sutcliffe IC, Trujillo ME, Goodfellow M (2012) A call to arms for systematists: revitalising the purpose and practises underpinning the description of novel microbial taxa. Antonie Van Leeuwenhoek 101(1):13-20

41. Wanner LA (2006) A survey of genetic variation in Streptomyces isolates causing potato common scab in the United States. Phytopathol 96(12):1363-1371

42. Wanner LA (2009) A patchwork of Streptomyces species isolated from potato common scab lesions in North America. American J Potato Res 86(4):247-264

43. Zhang Y, Bignell DR, Zuo R, Fan Q, Huguet-Tapia JC, Ding Y, Loria R (2016) Promiscuous pathogenicity islands and phylogeny of pathogenic Streptomyces spp. Mol Plant Microbe In 29(8):640-650

44. Zhang Y, Loria R (2017) Emergence of novel pathogenic Streptomyces species by site-specific accretion and cis-mobilization of pathogenicity islands. Mol Plant Microbe In 30(1):72-82

\section{Tables}


Table 1

GenBank accession numbers of Streptomyces isolates included for analyses in this study.

\begin{tabular}{|c|c|c|c|c|c|c|c|c|}
\hline \multirow[b]{2}{*}{ Species } & \multirow[b]{2}{*}{ Strain* } & \multicolumn{7}{|c|}{ GenBank accession numbers } \\
\hline & & $16 S$ & atpD & gyrB & recA & гров & $\operatorname{trp} B$ & Genome \\
\hline \multirow[t]{5}{*}{ S. werraensis } & FS39 & MK934920 & MN410458 & MK956276 & MK956493 & MN410504 & MN410521 & \\
\hline & FS73 & MK934946 & MK956758 & MK956289 & MK956521 & MK956396 & MK956632 & \\
\hline & FS96 & MK934970 & MK956780 & & MK956544 & MK956416 & MK956654 & \\
\hline & FS97 & MK934971 & MK956781 & & MK956545 & MK956417 & MK956655 & SAMN13430414 \\
\hline & 057 & MK934988 & MK956785 & MK956309 & MK956559 & MK956431 & MK956669 & SAMN13430417 \\
\hline \multirow{5}{*}{$\begin{array}{l}\text { S. } \\
\text { pseudogriseolus }\end{array}$} & FS33 & MK934914 & MK956734 & MK956271 & MK956488 & MN410499 & MN410516 & \\
\hline & FS38 & MK934919 & MN410457 & MK956275 & MK956492 & MN410503 & MN410520 & \\
\hline & FS41 & MK934922 & MN410459 & MK956277 & MK956495 & MN410505 & MN410522 & \\
\hline & FS94 & MK934968 & MK956778 & & MK956542 & MK956414 & MK956652 & SAMN13430413 \\
\hline & N92 & MK934979 & MK956784 & MK956308 & MK956552 & MK956424 & MK956662 & SAMN13430416 \\
\hline \multirow{5}{*}{$\begin{array}{l}\text { S. } \\
\text { resiliuntiscabiei }\end{array}$} & FS66 & MK934939 & MK956751 & MK956282 & MK956514 & MK956389 & MK956625 & SAMN16577100 \\
\hline & $\begin{array}{l}\text { FS70, } \\
\text { BD } \\
2226, \\
\text { LMG } \\
32103\end{array}$ & MK934943 & MK956755 & MK956286 & MK956518 & MK956393 & MK956629 & SAMN13430412 \\
\hline & FS75 & MK934948 & MK956759 & MK956291 & MK956523 & MK956398 & MK956634 & SAMN16577101 \\
\hline & FS82 & MK934955 & MK956766 & MK956298 & MK956530 & MK956404 & MK956641 & \\
\hline & N26 & MK934975 & MN410463 & & MK956548 & MK956420 & MK956658 & SAMN13430415 \\
\hline
\end{tabular}

* FS, N, O - Isolates stored in the Streptomyces bacterial collection at the ARC-VIMP, Pretoria, South Africa. BD - Plant Pathogenic and Plant Protecting Bacteria (PPPPB) Culture Collection, National Collection, ARC-PHP, Pretoria, South Africa. LMG - BCCM/LMG Bacteria Collection, University of Gent, Belgium.

\section{Figures}

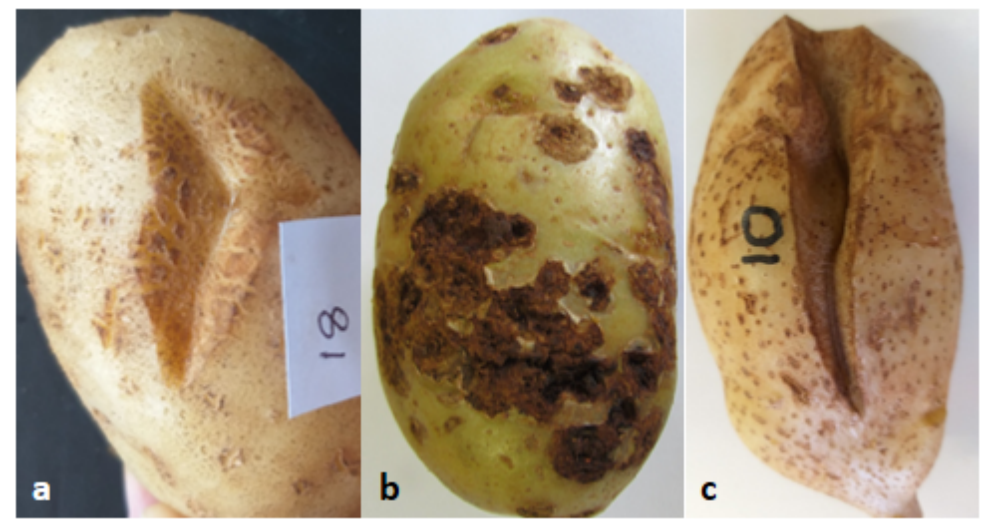

Figure 1

Potato tubers with a. fissure scab, b. common scab and c. growth crack. 


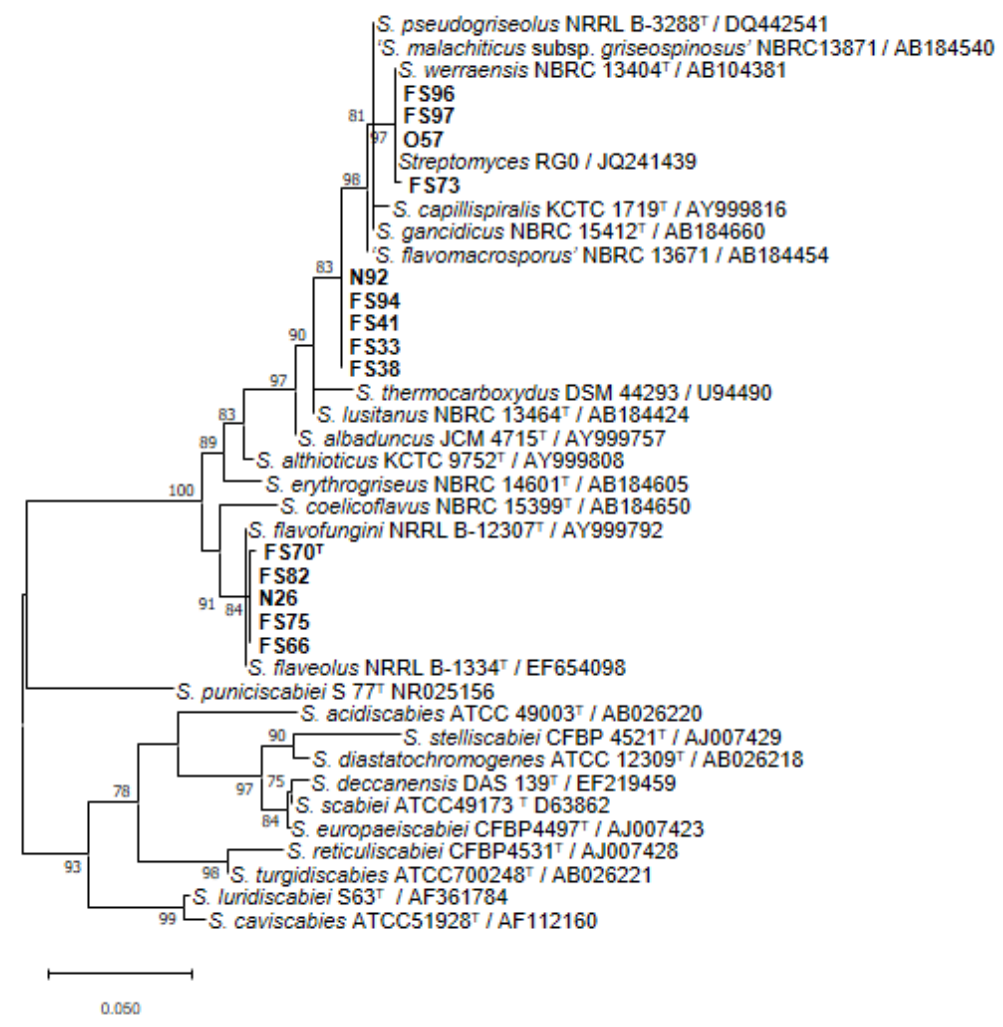

\section{Figure 2}

Midpoint rooted tree of Streptomyces species based on partial sequence of 16S rDNA gene region. 


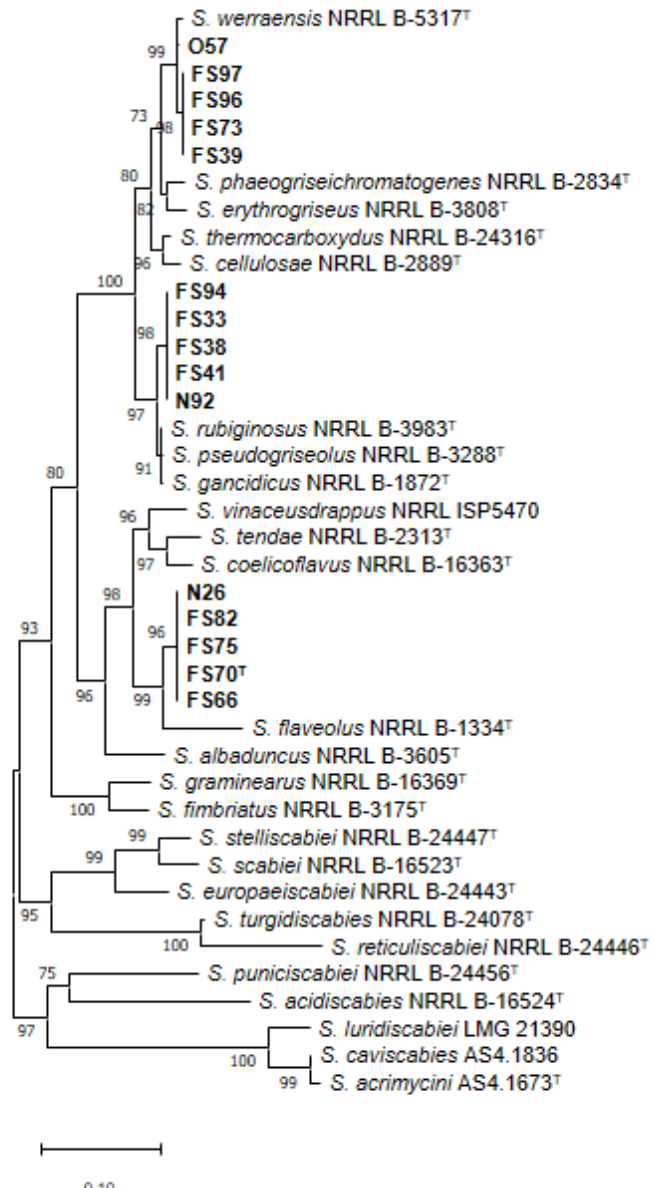

0.10

\section{Figure 3}

Midpoint rooted tree of combined house keeping genes atpD, gyrB, recA, rpoB, $\operatorname{trpB}$ of Streptomyces species. 


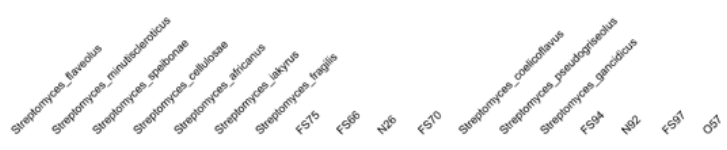

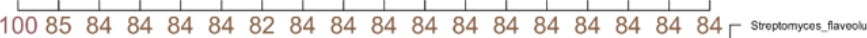

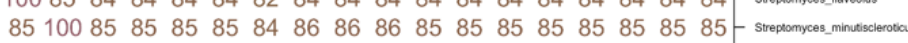

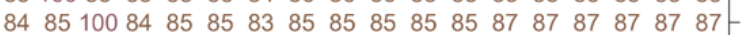

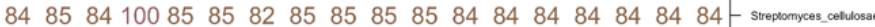

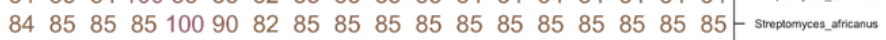

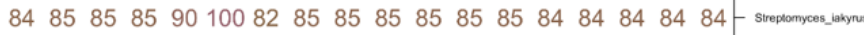

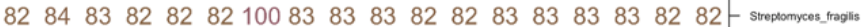
$\begin{array}{llllllllllllllllll}84 & 86 & 85 & 85 & 85 & 85 & 83 & 100100100100 & 88 & 85 & 85 & 85 & 85 & 85 & 85 & \text { F } \mathrm{F} 75\end{array}$ $\begin{array}{lllllllllllllllll}84 & 86 & 85 & 85 & 85 & 85 & 83 & 100100100100 & 88 & 85 & 85 & 85 & 85 & 85 & 85 & \text { F Fs6 }\end{array}$

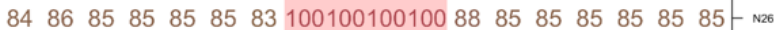
$\begin{array}{lllllllllllllllllll}84 & 85 & 85 & 85 & 85 & 85 & 82 & 100100100100 & 88 & 85 & 85 & 85 & 85 & 85 & 85 & \text { Fs70 }\end{array}$ $\begin{array}{lllllllllllllllllll}84 & 85 & 85 & 84 & 85 & 85 & 82 & 88 & 88 & 88 & 88 & 100 & 85 & 85 & 85 & 85 & 85 & 84 & -\end{array}$ \begin{tabular}{lllllllllllllllll|l}
84 & 85 & 87 & 84 & 85 & 85 & 83 & 85 & 85 & 85 & 85 & 85 & 100 & 99 & 97 & 97 & 93 & 93
\end{tabular}

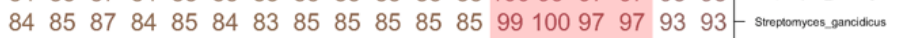
$\begin{array}{llllllllllllllllllll}84 & 85 & 87 & 84 & 85 & 84 & 83 & 85 & 85 & 85 & 85 & 85 & 97 & 97 & 100100 & 93 & 93 & \text { F Fs }\end{array}$

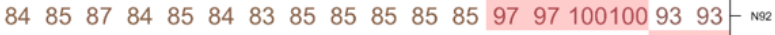

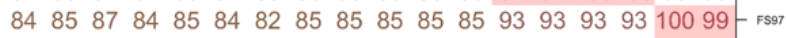

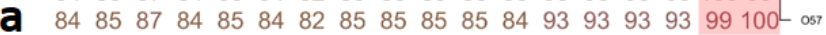

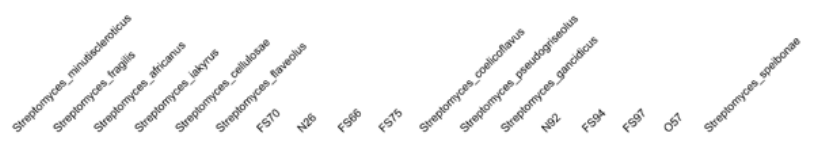

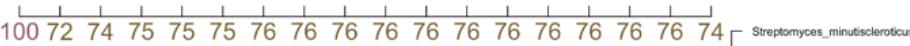

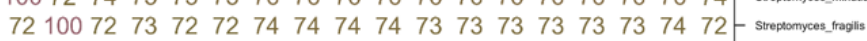

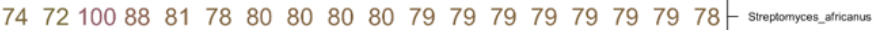

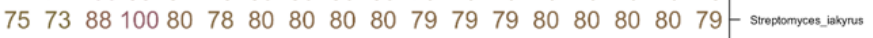

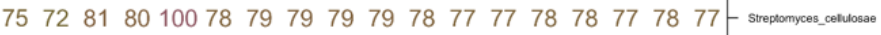

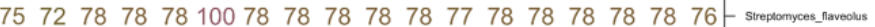
$\begin{array}{llllllllllllllll}76 & 74 & 80 & 80 & 79 & 78 & 100100100100 & 86 & 79 & 79 & 80 & 80 & 80 & 80 & 79 & \text { Fs70 }\end{array}$

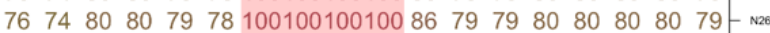

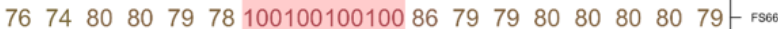
$\begin{array}{llllllllllllllll}76 & 74 & 80 & 80 & 79 & 78 & 100100100100 & 86 & 79 & 79 & 80 & 80 & 80 & 80 & 79 & \text { Fs }\end{array}$

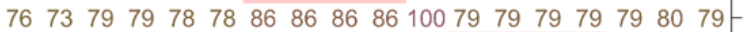

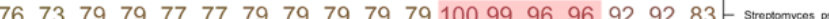

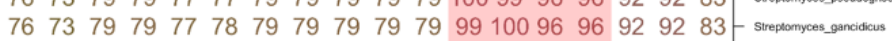

$\begin{array}{llllllllllllllllll}76 & 73 & 79 & 80 & 78 & 78 & 80 & 80 & 80 & 80 & 79 & 96 & 96 & 100100 & 92 & 92 & 84 & \text { - N92 }\end{array}$

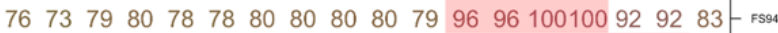

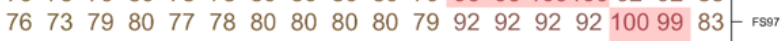

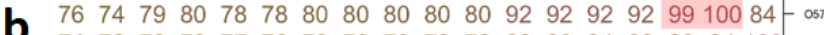

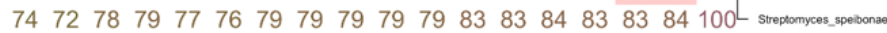

\section{Figure 4}

a. Average Nucleotide Identity matrix, b. Average Amino acid Identity matrix of Streptomyces species, based on full genome sequences.
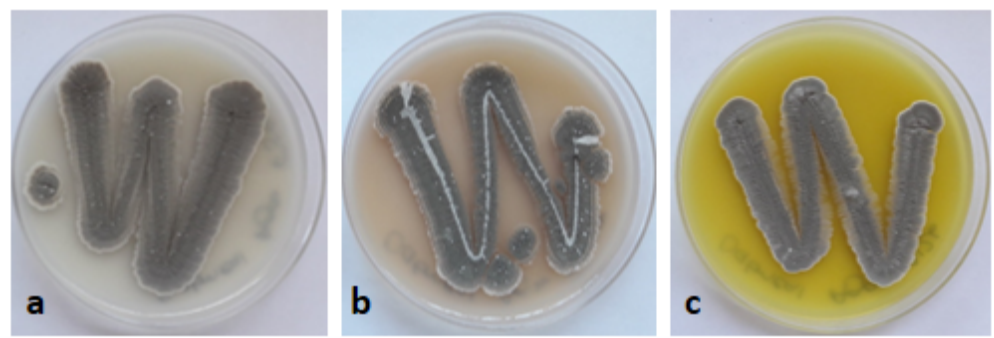

\section{Figure 5}

Streptomyces cultures on OMA after 14 days: a. clade 1 (S. werraensis), b. clade 2 (S. pseudogriseolus), and c. clade 3 (S. resiliuntiscabiei sp. nov.). 

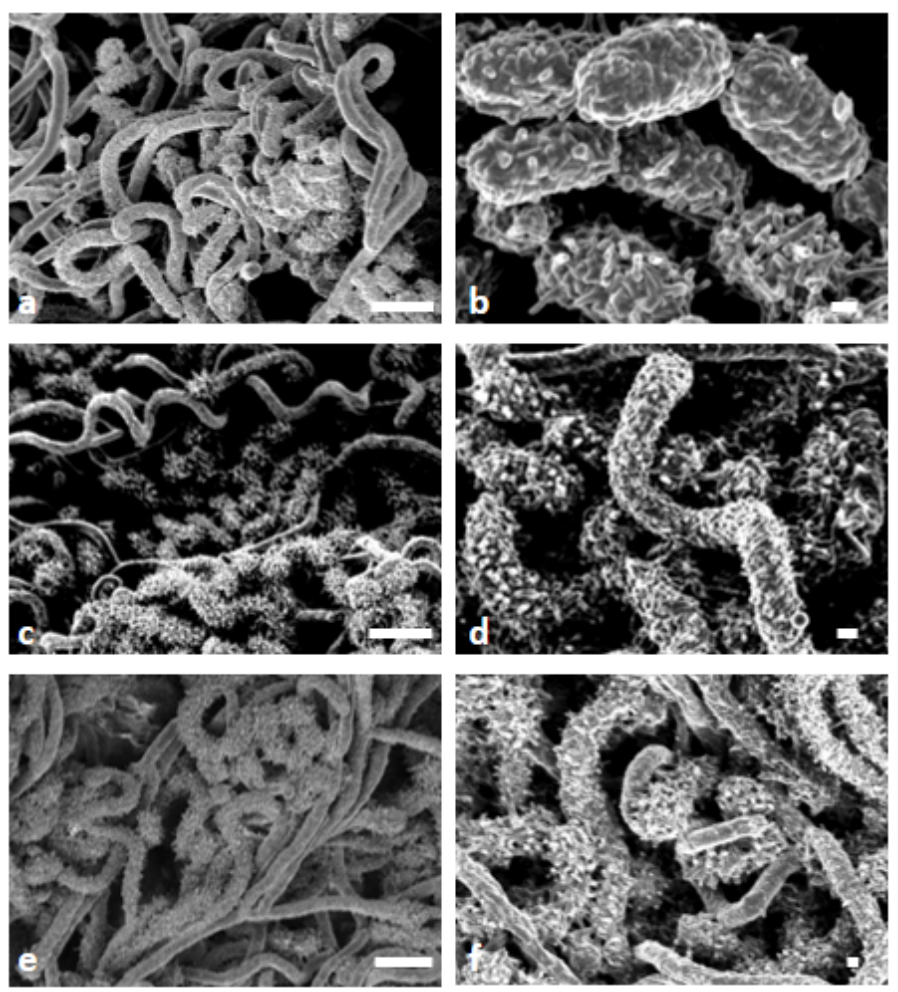

Figure 6

SEM images of Streptomyces isolates obtained from fissure scab symptoms: a. S. werraensis mycelia, b. S. werraensis spores, c. S. pseudogriseolus mycelia in spirals, d. S. pseudogriseolus spores and spirals, e. clade 3 (S. resiliuntiscabiei sp. nov.) mycelia, and f. clade 3 spores. Scale bars: a, c, e = $2 \mu \mathrm{m}, \mathrm{b}, \mathrm{d}, \mathrm{e}=200 \mathrm{~nm}$.

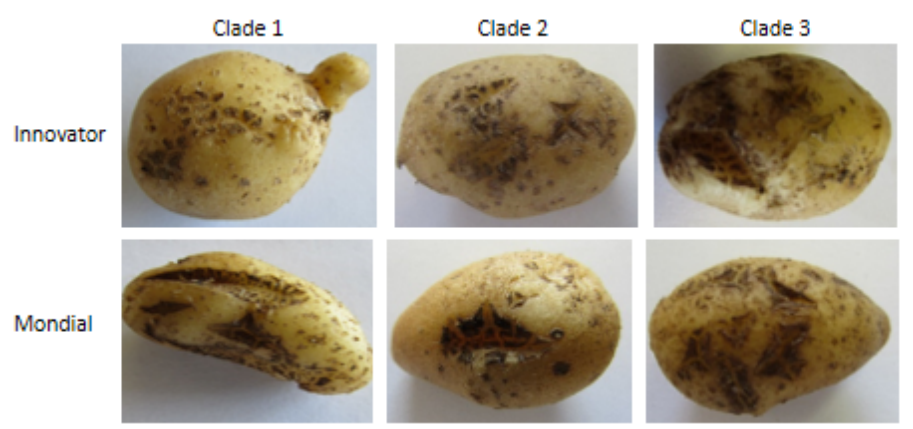

\section{Figure 7}

Symptoms on potato tubers after inoculation with Streptomyces species. Top row cv. Innovator and bottom row cv. Mondial. 


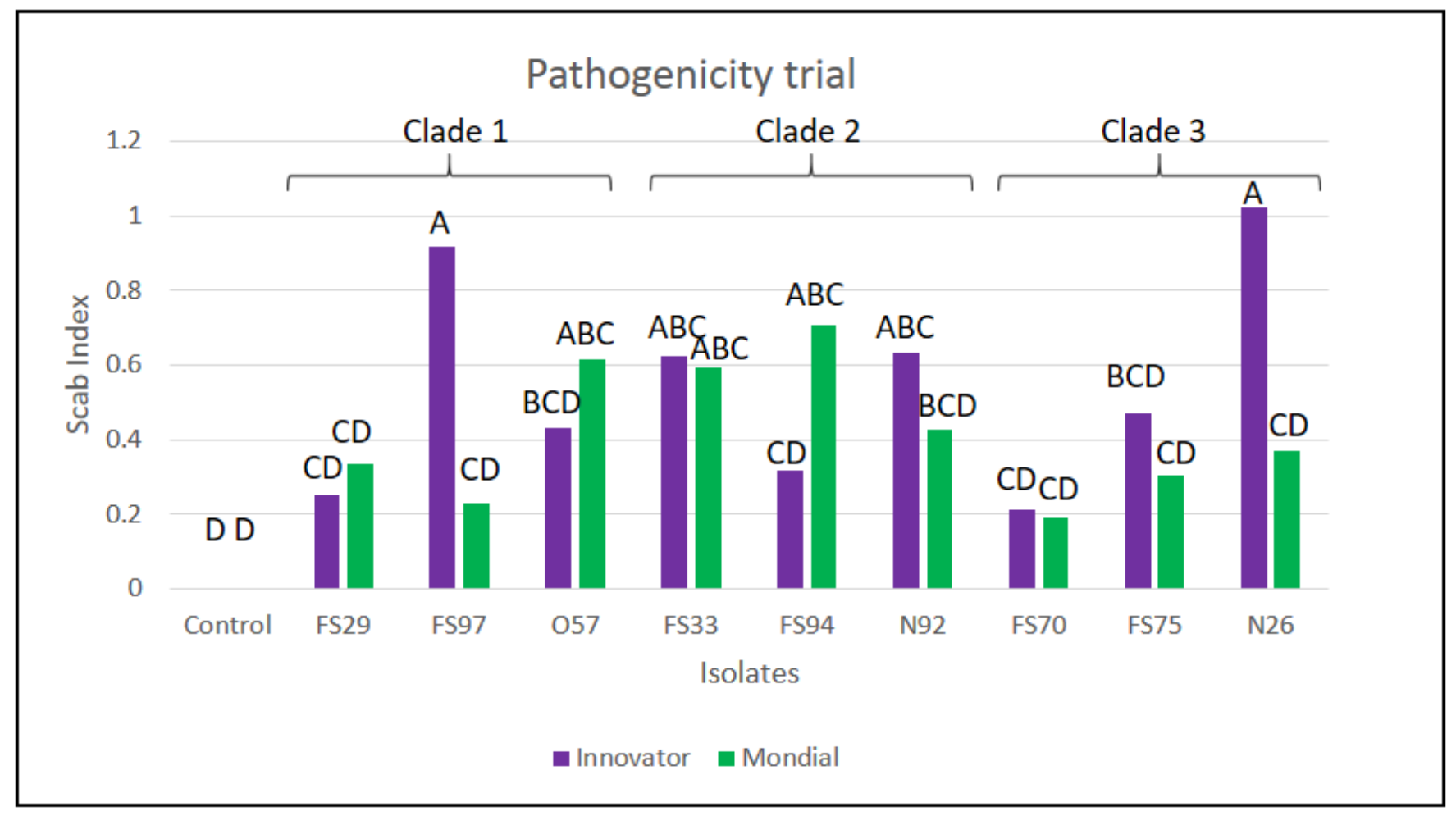

\section{Figure 8}

Results from glasshouse trial showing scab index on cv. Innovator and Mondial. Different letters on top of bars indicate significant differences.

\section{Supplementary Files}

This is a list of supplementary files associated with this preprint. Click to download.

- SupplFigStreptomycesspp.16S.pdf 